\title{
BOOK ReVIEw/COMPTES RENDU
}

Donatella della Porta, ed., Democracy in Social Movements. New York: Palgrave Macmillan, 2009, 304 pp. \$US 90.00 hardcover (978-0-230- 21883-3)

A

$n$ enduring question in the study of social movements is the extent cratic ideals they advocate in their internal organizational operations. Beginning with Robert Michel's assertion that "with the advance of organization, democracy tends to decline," debates about oligarchy, hierarchy, and participatory democracy have long concerned social scientists and activists alike. Building on this vast body of research, the contributions to Donatella della Porta's edited volume, Democracy in Social Movements, examine whether the democratic experimentation of the Global Justice Movement (GJM) can extend this debate.

Beginning with the premise that participatory democracy is part of a larger set of alternative decision-making strategies, the authors focus on debates about "deliberative democracy" which refers to "decisional processes, in which, under conditions of equality, inclusiveness, and transparency, a communicative process based on reason (the strength of a good argument) may transform individual preferences" (p. 1). In this view, definitions of public goods are developed through deliberative, reasoned processes that allow for the emergence of a consensus. By focusing on this vision, the authors attempt to draw the emphasis away from the reality or extent of participation towards democratic innovation taking place within the GJM .

The authors point to the Social Forum process as the root of the emerging shared values of deliberation and consensus within the GJM. Beginning in 2001 in Porto Alegre Brazil, these annual meetings of activists and organizations represent a unique democratic innovation, della Porta argues, because they are open, public spaces where the organizations and individual activists of the GJM meet to strategize and develop common values and identities. Despite the uniqueness of the Social Forums, it is difficult to imagine that, given the heterogeneity of the GJM, there is any uniform acceptance of one form of democracy. This is where the strength of this volume lies.

The contributors stress the spread of democratic principles throughout the movement. However, a key objective of the book is to under- 
stand and explain how GJM organizations differ in their conceptions of democracy. The authors empirically explore factors that shape differential acceptance of a variety of democratic values within the GJM. Accordingly, several chapters are dedicated to examining explanatory factors, including cultural and structural factors, generational factors, and organizational characteristics such as size, budget, structure and period of origin. However, it is also argued that while it shapes different levels of acceptance of democratic principles, this plurality also motivates the search for forms of participation that respect "individual subjectivity, avoiding exclusive commitments and vertical control"(p. 75). Thus, the book both describes the variety of conceptions of democracy found with the GJM and examines the factors that facilitate and/or impede the development of shared commitments to democratic principles.

Because it is "organizationally fluid, strategically broad, and tolerant of diversity" (p. 16), the GJM can be troublesome for scholars. This volume provides those interested in the movement with some welcome tools. Chapters 1 and 10 in particular focus on answering some basic questions about the movement: is there $a$ GJM? To what extent is it global? Is the movement new? By sampling the organizational composition of the movement, the self-identification of actors with movement values, and their repertoires of action the authors give some substance to claims about the shared attributes of the movement. The vast variety of networks, organizations, individuals and interests are linked, della Porta argues, by four shared concerns: "calls for rights, social justice, democracy from below and the global nature of the action" (p. 21). It is this multi-issue discourse, flexible networking, and the ongoing discussion of deliberative democracy which ultimately define the movement's novelty.

It is well-established that social movements struggle with their desire to present alternative visions of democracy while also representing these visions in their internal organizational operations. This book takes on the task of investigating this dynamic within the "movement of movements" by way of an empirical examination of the issue: to what extent is there a measurable commitment to these alternative organizing principles within the organizations of the GJM? What factors can be said to explain varying levels of commitment to these principles? Is there an emerging consensus surrounding the democratic visions and practices? And although this empirical approach is the strength of the book it is also a weakness. The book's multi-method research includes an impressive amount of data from semi-structured interviews, websites, organizational documents, activist surveys, and participant observation gathered in the Democracy in Europe and the Mobilization of the Society (DEMOS) project. This research focuses primarily on six European countries. But 
one of the central ideals of the GJM is the unification of activists from the Global South and North, and how complete can our understanding be without data from the Global South? This omission reflects the difficulties of conducting research on such an amorphous movement. Still, the claim that democratic innovation is rapidly spreading throughout the networks of the GJM would be much more compelling if it was based on data from organizations including, but not exclusive to Europe. How different are conceptions of deliberative democracy in organizations based outside of the Global North?

Despite this criticism, this book's contribution to the literature on alternative organizing is significant. Questions of democratic decisionmaking are not limited to the study of social movements, and this volume will appeal to those teaching in a wide range of sociological areas. Moreover, for those with an interest in the study of contemporary movements, the book usefully outlines the basic contours of the GJM, arguably one of the most important movements currently in operation.

University of Ottawa

Kathleen Rodgers

Kathleen Rodgers is an Assistant Professor in the department of Sociology and Anthropology at the University of Ottawa. Her recent publications include "When do Opportunities become Trade-offs for Social Movement Organizations? Assessing Media Impact in the Global Human Rights Movement," Canadian Journal of Sociology (January 2010), and “"Anger is Why We're all Here': Mobilizing and Managing Emotions in a Professional Social Movement Organization," Social Movement Studies (June 2010). 